\title{
Similar seed dispersal systems by local frugivorous birds in native and alien plant species in a coastal seawall forest
}

\author{
Bin Liu ${ }^{1,2}$, Guohai Wang ${ }^{1}$, Yuting An ${ }^{2}$, Dandan Xue ${ }^{2}$, Libo Wang $^{2}$, Changhu Lu ${ }^{\text {Corresp. } 1}$ \\ ${ }^{1}$ College of Biology and the Environment, Nanjing Forestry University, Nanjing, Jiangsu, China \\ 2 Management Bureau of Dafeng Milu National Nature Reserve, Yancheng, Jiangsu, China \\ Corresponding Author: Changhu Lu \\ Email address: luchanghu@njfu.com.cn
}

Frugivorous birds play an important role in seed dispersal. Alien plant species' seeds are dispersed by local birds in order to establish populations in new habitats. Alien plant species that produce fruits similar to that of native species have the potential to attract local birds, creating new mutualistic systems that are similar to the local ones. In autumn 2018 and 2019, we studied the seed dispersal systems of an alien plant species, Phytolacca americana, and a native species, Cayratia japonica, in a coastal seawall forest. Both plant species' fruit, frugivorous bird foraging behaviors, seed germination rates, and seedling microhabitats were examined to determine whether the alien species had a similar seed dispersal system to that of the native species. Our results showed that $P$. americana and $C$. japonica had similar fruit type, color, and ripening period. There was a positive correlation between the percentage rate of fruit ripening and the percentage rate of fruit missing for both plant species, indicating that local frugivorous birds have the potential to sufficiently disperse the alien seeds to enable its spread in the coastal seawall forest (simple linear regression, $P$. americana: $\beta=0.863 \pm 0.017, R_{\text {adj }}^{2}=0.978, P<0.01 ; C$. japonica: $\beta=0.787 \pm 0.034, R_{\text {adj }}^{2}=0.898, P<0.01$ ). Eleven bird species consumed the fruits of both the alien species and native species during the study period. Similar results were shown across alien and native species in bird foraging behavior (feeding frequency, feeding duration and first stop distance) indicating that a similar seed dispersal relationship had been established between local frugivorous and both plant species. The alien plant had a higher number of fruits carried by birds, suggesting that $P$. americana had a slightly higher fruit consumption than that of $C$. japonica ( $t$-test, $P<0.01$ ). Alien plant seedlings grow more abundant in forest gap microhabitat ( $t$-test, $P<0.01)$. Our results confirmed that bird digestion promotes seed germination success in both plant species. Our study suggests that in a narrow coastal seawall forest, alien plant species can successfully establish their populations by relying on similar seed dispersal systems as the 
local species. 


\section{Similar seed dispersal systems by local frugivorous}

3 birds in native and alien plant species in a coastal

4 seawall forest

5

6

7

8

9

10

11

12

13

14

15

16

17

18

19

20

21

22

23

24

25

26

27

28

29

30

31

32

33

34

35

36

37

38

Bin Liu ${ }^{1,2}$, Guohai Wang ${ }^{1}$, Yuting An², Dandan Xue ${ }^{2}$, Libo Wang ${ }^{2}$, Changhu Lu ${ }^{1}$

${ }^{1}$ College of Biology and the Environment, Nanjing Forestry University, Nanjing, Jiangsu, China

${ }^{2}$ Management Bureau of Dafeng Milu National Nature Reserve, Yancheng, Jiangsu, China

Corresponding Author:

Changhu $\mathrm{Lu}^{1}$

Nanjing, Jiangsu, China

Email address: luchanghu@njfu.com.cn

\section{Abstract}

Frugivorous birds play an important role in seed dispersal. Alien plant species' seeds are dispersed by local birds in order to establish populations in new habitats. Alien plant species that produce fruits similar to that of native species have the potential to attract local birds, creating new mutualistic systems that are similar to the local ones. In autumn 2018 and 2019, we studied the seed dispersal systems of an alien plant species, Phytolacca americana, and a native species, Cayratia japonica, in a coastal seawall forest. Both plant species' fruit, frugivorous bird foraging behaviors, seed germination rates, and seedling microhabitats were examined to determine whether the alien species had a similar seed dispersal system to that of the native species. Our results showed that $P$. americana and $C$. japonica had similar fruit type, color, and ripening period. There was a positive correlation between the percentage rate of fruit ripening and the percentage rate of fruit missing for both plant species, indicating that local frugivorous birds have the potential to sufficiently disperse the alien seeds to enable its spread in the coastal seawall forest (simple linear regression, $P$. americana: $\beta=0.863 \pm 0.017, R_{a d j}^{2}=0.978, P<0.01 ; C$. japonica: $\beta=0.787 \pm 0.034, R_{a d j}^{2}=0.898, P<0.01$ ). Eleven bird species consumed the fruits of both the alien species and native species during the study period. Similar results were shown across alien and native species in bird foraging behavior (feeding frequency, feeding duration and first stop distance) indicating that a similar seed dispersal relationship had been established between local frugivorous and both plant species. The alien plant had a higher number of fruits carried by birds, suggesting that $P$. americana had a slightly higher fruit consumption than that of $C$.

japonica $(t$-test, $P<0.01)$. Alien plant seedlings grow more abundant in forest gap microhabitat $(t$-test, $P<0.01)$. Our results confirmed that bird digestion promotes seed germination success in both plant species. Our study suggests that in a narrow coastal seawall forest, alien plant species

Peer) reviewing PDF | (2020:11:55858:2:0:NEW 27 May 2021) 
39

40

41

42

43

44

45

46

47

48

49

50

51

52

53

54

55

56

57

58

59

60

61

62

63

64

65

66

67

68

69

70

71

72

73

74

75

76

77

78

can successfully establish their populations by relying on similar seed dispersal systems as the local species.

\section{Introduction}

Seed dispersal is critical for the maintenance of plant populations (Butler et al., 2007; Wilson \& Downs, 2012) and alien species invasions (Schierenbeck, 2004; Buckley et al., 2006). Certain plant species rely on wind, water, or other abiotic forces to spread their seeds far away, while others depend on frugivorous birds for seed dispersal (Moles et al., 2005; Prado, 2013). Over many years of evolution, a reciprocal relationship between plants and frugivorous birds has been established (Lu, 2003; Li et al., 2019) in which plants provide necessary nutrients for birds and in return, birds disperse seeds to other habitats and improve plant regeneration (Camargo et al., 2019; Morán-López et al., 2020; Galindo-González, Guevara, \& Sosa, 2000). Birds are among the most common seed disperser worldwide, and bird-mediated seed dispersal is one of the most important ecological processes (Saavedra et al., 2014; Wang \& Ives, 2017).

Many plant species, including invasive alien plants (Thabethe et al., 2015), rely on frugivorous birds for seed dispersal (Schleuning et al., 2011; Duan, Goodale, \& Quan, 2013; Lovas-Kiss, 2020). It is crucial for these alien plant species to establish an adaptation mechanism in order to settle down, build populations, and spread in their new habitat. If alien plants with fleshy fruits do not establish effective dispersal interactions with frugivores present in the local area (Drummond, 2005; Kollmann et al., 2007), they will fail to settle in a new environment or will have greatly reduced potential for spreading and out-competing native plants (Aslan, 2011).

Many studies have looked at the relationship between alien plants and the local birds that feed on their fruits and disperse their seeds (Renne et al., 2002; Gosper, Stansbury, \& VivianSmith, 2005). Most alien plant species have different traits when compared to those of native species. For example, a study in a coastal belt forest in South Africa showed that plants effectively dispersed by birds were small-seeded, open-habitat species with longer fruiting periods (Bitanni et al., 2020). In northern California, a study on the proportion of fruits removed by birds showed that all three non-native species, whose fruits differed greatly with native plants in both type and appearance, were assimilated into local bird diets and their dispersal by birds was not limited (Aslan, 2011). A study on secondary forest sites on Bonin Island, Japan showed that introduced plant fruits were dispersed differently by native and non-native bird species, and new mutualistic relationships involving native and introduced birds and plants were established in the seed-dispersal system (Kawakami, Frederiksen, \& Vestergaard, 2009). Whether seed dispersal systems established by alien plant species are different compared to those of native species has not been determined.

Phytolacca americana, an alien fleshy-fruited plant species, and Cayratia japonica, a native climbing fleshy-fruited plant, coexist in a coastal seawall forest in the Yellow Sea wetland, Jiangsu Province, China. The forest is a long corridor with planted trees that can provide migration channels, foraging places, and breeding sites for different kinds of birds (Liu et al., 2020). Phytolacca americana seed dispersal has been reported in both China and its native land 
79

80

81

82

83

84

85

86

87

88

89

90

91

92

93

94

95

96

97

98

99

100

101

102

103

104

105

106

107

108

109

110

111

112

113

114

115

116

117

118

(Mcdonnell et al., 1984; Li et al., 2017), but C. japonica seed dispersal has not been reported. In previous observations of the coastal seawall forest, fruits of both plant species were consumed in autumn by groups of frugivorous birds. Therefore, this forest is an excellent site to study the seed dispersal systems of native and introduced plant species by local frugivorous birds.

We predict that the alien plant species $P$. americana may establish a mutual relationship with the local birds in seed dispersal. Since both $C$. japonica and P. americana were the dominant fruit plants in autumn in the study site, we selected them to examine the seed dispersal systems between the alien plant species and local birds. We compared the two plants' seed dispersal systems according to their fruit characteristics, bird foraging behaviors, seedling microhabitat growth, and seed germination rates.

\section{Materials \& Methods}

\section{Ethics statement}

Field studies were conducted with permission from the Management Bureau of Dafeng Milu

National Nature Reserve.

\section{Study site}

The field work was conducted in the Dongchuan coastal seawall forest in Dafeng Milu National Nature Reserve, Jiangsu Province, China $\left(32^{\circ} 59^{\prime} \mathrm{N} \sim 33^{\circ} 03^{\prime} \mathrm{N}, 120^{\circ} 47^{\prime} \mathrm{E} \sim 120^{\circ} 53^{\prime} \mathrm{E}\right)$. The forest was planted in the 1990s, and was mainly used for windbreak and dike consolidation. The region is characterized by a transition climate between subtropical and warm temperate. The mean annual precipitation is approximately $1,068 \mathrm{~mm}$ (concentrated in summer) and the mean annual temperature is $14.1{ }^{\circ} \mathrm{C}$. The vegetation is dominated by Robinia pseudoacacia, with smaller areas of Metasequoia glyptostroboides and Populus canadensis. The width of the forest is about 20 50 $\mathrm{m}$. One side of the forest is an intertidal zone with the main vegetation types Spartina alterniflora, Suaeda glauca, Phragmites communis, and Imperata cylindrica, and the other side is farmland and pond culture. Annual typhoons blow over the trees, exposing many open forest gaps. Many bird species live in the forest, including the light-vented bulbul (Pycnonotus sinensis), common blackbird (Turdus merula), and black-billed magpie (Pica pica). From April to May and September to October, many passerines, mainly warblers and flycatchers, travel through the forest in order to complete their migration life cycle. In autumn, this area also has a small number of other fruiting, such as Lycium barbarum, Sapium sebiferum, Ligustrum lucidum, and Paederia scandens.

\section{Field observation}

\section{Fruit and seedling investigations}

From September to October 2018, we randomly chose 20 focal plants from each target species along the coastal seawall forest. The fruit type, size, shape, and color, ripening period, and height were recorded across 20 sampled individuals from each species. The fruit's size $(\mathrm{mm})$ was defined as its diameter measured by a caliper ( $n=20$ for each plant species). The fruit's color was 
119 the color of peel. The ripening period, dates of the natural phenology of the plants, was from

120 September to October. The maximum fruit's height was defined by measuring the highest fruits

121 and taking the average value from the 20 sampled individuals. To calculate the rates of ripe and

122 missing fruits, we counted the number of ripe fruits from five randomly sampled individuals

123 across each species every 5 days. The number of fruits was the total fruits on one sampled tree.

124 The missing fruits was the difference between the number of total fruits and the number of total

125 fruits 5 days later. Seedlings were found within plots ( $r=25 \mathrm{~m}, n=15$ for each plant species)

126 around the individual selected plants. Seedling microhabitats were inspected at the same time:

127 the forest gap was formed after trees were fallen by wind and there was enough sunshine for

128 seedlings, and the understory was where the sunlight could hardly reach the ground. Tree density

129 was measured by sampling method. 20 plots $\left(10 \times 10 \mathrm{~m}^{2}\right)$ were randomly selected along the

130 forest. Each species' plant density (the number of plants divided by the area of the plots) was

131 investigated in the study site.

132

133

\section{Bird feeding behaviors}

134 We observed the behaviors of birds feeding on the two plant species' fruit in the forest between

135 September and October 2018 and 2019. The focal individual sampling method was used to

136 quantify visitation and fruit removal by birds at every sampled plant individual. 20 focal

137 individuals of each plant species were investigated. Since most bird foraging occurred at dusk

138 and dawn, observations were carried out from 6 am to 9 am, or 4 pm to $6 \mathrm{pm}$ on sunny days. The

139 total observation time was 85 hours. Each observation continued until the birds had disappeared.

140 We counted the number of fruits swallowed and pecked by each bird species and the total

141 foraging time in every observation. The focal bird's first stopping distance (the distance between

142 the first resting place of the visiting birds and the sample plant, also regarded as the potential

143 minimum seed dispersal distance) was measured using a laser range finder. We calculated the

144 total number of feeding visits by each bird on each plant species across the study period. The

145 average feeding duration (in seconds) on each plant species was also recorded.

146

\section{Seed germination trials}

148 We compared the cumulative germination success of defecated seeds by local frugivorous birds

149 with that of hand-cleaned seeds and intact fruits. All seeds and fruits were collected from the

150 study site in October 2018. Seed germination experiments were carried out from June 20 to

151 August 20, 2019. Defecated seeds from each individual bird, hand-cleaned seeds, and the intact

152 fruits were planted in separate bowls with a diameter of $10 \mathrm{~cm}$. Each experimental group

153 contained 100 seeds, planted equally across 20 bowls. All bowls were then placed in a laboratory

154 balcony and watered daily during the first month. Seeds were considered germinated when

155 seedlings emerged through the soil surface. The number of seeds germinated was recorded at

156 least once every 15 days between early June and mid-August. Once counted, seedlings were

157 removed from the tray.

158 
159

160

161

162

163

164

165

166

167

168

169

170

171

172

173

174

175

176

177

178

179

180

181

182

183

184

185

186

187

188

189

190

191

192

193

194

195

196

197

\section{Data analysis}

We compared the maximum fruit's height and fruit size of each plant species using a $t$-test. A $t$ test was also used to compare the density of the seedling microhabitat growth. We used simple linear regression to test the correlation between each species' fruit ripening rate and missing rate. We used a $t$-test to compare the total feeding frequency of each bird species on each plant species, the average feeding duration (in seconds), the amount of fruit consumed per visit, and the first stopping distance of the focal bird. If the data distribution was not normal before or after square root treatment, we used the $U$-test. ANOVA tests were used to compare the germination success of defecated seeds to hand-cleaned seeds and intact fruits. After that, LSD test was used to compare the difference between each other. All analyses were performed using SPSS 26.0 and the software package R version 3.4.4 (R Core Team 2018) was used to make the plots. The level of statistical significance was set at $P<0.05$.

\section{Results}

\section{Fruit characteristics of plant species}

In autumn, $P$. americana and C. japonica are the most common fruiting species in the coastal seawall forest. Both fruit types are berry. When ripe, their colors change to black or purpleblack. There was a significant difference in the fruit size between the species $(t$-test, $t=8.252$, $d f=38, P<0.01$ ) (Table 1). Cayratia japonica has bigger fruits than P. americana.

Phytolacca americana mainly grew in the forest gap habitat, while $C$. japonica was widely distributed in the understory along the seawall forest. The fruit ripening period of the two plant species basically overlapped, and both ripened between August and October. There was a significant difference in the height of fruit distribution between the two species, with higher of $P$. americana ( $U$-test, $Z=-5.420, P<0.05, n=40$ ). Fruit height of $P$. americana is higher than $C$. japonica.

\section{Fruit feeding and seed dispersal by frugivorous birds}

Ripe fruits were constantly eaten by frugivores, and no other animal groups were observed to eat $P$. americana or C. japonica fruits during the daytime. The relationship between the percentage of fully-ripe fruits and the percentage of fruits taken by birds showed a significant positive correlation for both plant species (simple linear regression, $P$. americana: $\beta=0.863 \pm 0.017$, $R_{a d j}^{2}=0.978, P<0.01 ; C$. japonica: $\left.\beta=0.787 \pm 0.034, R_{a d j}^{2}=0.898, P<0.01\right)$ (Fig. 1). This suggested that the more ripen fruits, the greater proportion of missing fruits were eaten by birds or fallen on the ground.

A total of 11 bird species were observed feeding on the fruits. Vinous-throated parrotbill (Paradoxornis webbianus), blue-and-white flycatcher (Cyanoptila cyanomelana), and greybacked thrush (Turdus hortulorum) were the three species that only fed on Phytolacca americana. Black-napped oriole (Oriolus chinensis) was the species that only fed on C. japonica. The rest of the bird species fed on both fruits of the two plants (Fig. 2). 
198

199

200

201

202

203

204

205

206

207

208

209

210

211

212

213

214

215

216

217

218

219

220

221

222

223

224

225

226

227

228

229

230

231

232

233

234

235

236

237

The Pycnonotus sinensis and Pica pica had the highest feeding frequencies on $P$. americana and C. japonica, respectively. Pycnonotus sinensis and Sturnus cineraceus had the longest foraging times on Phytolacca americana and Cayratia japonica fruits, respectively. The Sturnus cineraceus was the species with the furthest first stopping distance after feeding on both plants (Table 2). However, there were no significant differences in bird feeding frequency ( $U$-test, $Z=$ 1.116, $P>0.05, n=18$ ), feeding duration ( $t$-test, $t=1.960, d f=16, P>0.05$ ), or first stopping distance ( $t$-test, $t=1.401, d f=16, P>0.05$ ) between $P$. americana and $C$. japonica. However, the number of $P$. americana fruits consumed per visit was significantly larger than the number of $C$.

japonica fruits consumed ( $t$-test, $t=-3.941, d f=16, P<0.01$ ) (Table 2).

\section{Seed germination rate}

The seed germination rate of intact fruits was lower than both hand-cleaned seeds and defecated seeds from both plant species. Phytolacca americana's final seed germination rates across the three different groups were as follows: $79 \%$ for defecated seeds, $60 \%$ for hand-cleaned seeds, and 13\% for intact fruits (Fig. 3). Additionally, C. japonica's final seed germination rates were $87 \%, 71 \%$, and 18\%, respectively (Fig. 3). There was a significant difference of seed germination rates across the different groups between $P$. americana (ANOVA: $F_{2,15}=13.283$, $P<0.01$ ) and $C$. japonica (ANOVA: $F_{2,15}=4.591, P<0.05$ ). The seed germination of intact $P$. americana fruits was significantly lower compared to hand-cleaned seeds (LSD-test, $P<0.01$ ) and defecated seeds (LSD-test, $P<0.01$ ). The same result was shown in $C$. japonica. This showed that fruit pulp removal by local frugivorous birds' digestion or other methods could promote seed germination success across both plant species.

\section{Seedling microhabitats}

We randomly found $300 P$. americana seedlings and 280 C. japonica seedlings along the seawall forest in the study site. There were differences in microhabitat characteristics between the two plant species. Phytolacca americana seedlings preferred the forest gap habitat, and significantly more seedlings were found in the forest gap habitat than in the understory habitat ( $t$-test, $t=5.684$, $d f=28, P<0.01$ ) (Fig. 4). However, $C$. japonica seedlings did not show an obvious preference when selecting a microhabitat ( $t$-test, $t=0.092, d f=28, P>0.05)$ (Fig. 4).

\section{Discussion}

\section{Similar fruit characteristics between the two plant species}

Bird-mediated seed dispersal is important for the establishment of many fleshy-fruited plant species (Wenny, 2001). Many alien plants with fleshy fruits are able to establish effective dispersal interactions with local birds based on having attractive fruit characteristics that are similar to those of native plants (Gosper, Stansbury, \& Vivian-Smith, 2005). Our study showed that the alien $P$. americana species had similar characteristics (e.g., fruit type, shape, color when ripe, and ripening period) to the native $C$. japonica species (Table 1). This similarity suggests that the alien species $P$. americana has great potential to have its seeds dispersed by local 
238 frugivorous birds that have already established a positive relationship with the native plant 239 species C. japonica.

240 Previous studies have found that small fruits and seeds are more effectively removed and 241 dispersed than larger ones (Rey et al., 1997), and birds prefer visiting trees with larger crop sizes 242 (Sallabanks, 1993; Korine, Kalko, \& Herre, 2000). A study in a coastal belt forest in South 243 Africa found that fleshy-fruited invasion plant species effectively dispersed by birds were small244 seeded, open-habitat species with longer fruiting lengths compared to native plant species (Bitani 245 et al., 2020). If the former conclusion is true, and based on the fact that $P$. americana has smaller fruit size but more seeds than C. japonica (Mcdonnell et al., 1984; Hansen \& Goertzen, 2006), P. americana could use these traits as an advantage over $C$. japonica in order to improve its dispersion efficiency.

The forest gap microhabitat formed by light disturbance was more suitable for the growth of alien plant species (Willamson \& Fitter, 1996; Ridenour \& Callaway, 2001). We found that alien plant species seedlings tended to occupy the forest gap microhabitat, which was more suitable for seedling growth. However, the native plant seedlings showed no preference in microhabitat selection. This suggested that alien plant species seedlings had developmental potential for successful population regeneration in the coastal seawall forest. These results were consistent with the findings of Burnham \& Lee (2010) and Martins et al. (2004).

\section{Similar seed dispersal systems}

A fruiting species can be consumed by a variety of potential bird dispersers, and a potential bird disperser can remove a variety of fruit species (Dugger et al., 2018; Schneiberg et al., 2020). In our study, seven out of 11 local frugivorous birds consumed fruits from both plant species, suggesting that a stable relationship between the alien plant and local birds had already been established. Three bird species were found to only consume the alien species, showing that it had a wider popularity with local bird species (Whelan \& Willson, 1994; Levey \& Martínez del Rio, 2001). Ten out of 11 and eight out of 11 bird species who ingested the whole fruit may be potential seed dispersers of the alien species and the native species in study site, respectively. Four bird species were pecking birds since pecking may have damaged the seeds (Table 2).

Pycnonotus sinensis is a small and common frugivorous bird species that we studied during our field observation. Because of the lack of insects, ripening fruits were their main food resource in the coastal seawall forest in autumn. We typically observed three to five Pycnonotus sinensis individuals foraging on Phytolacca americana trees with large crop sizes and purpleblack ripe fruits. Ultimately, Pycnonotus sinensis interacted the most with the alien species and was its main seed disperser.

Overall, we did not find an obvious pattern of preference across the local birds' selection and utilization of fruits from these two plants, which reflected the degree of similarity between the introduced plant species $P$. americana and the native species $C$. japonica. We found some different feeding behaviors between the two plant species, but according to the number of consumed fruits, $P$. americana showed more easily used by birds. We found that the frugivores 
278 feeding on the fruits were mostly resident birds. Migratory birds contributed less to seed

279 dispersal according to the lower feed frequency and shorter feed duration of the three migratory

280 species, Oriolus chinensis, Turdus hortulorum, and Cyanoptila cyanomelana. Therefore, we

281 concluded that resident birds were the main contributors to P. americana and C. japonica seed

282 dispersal. This may be due to the fact that birds migrating through the seawall forest in autumn

283 were mostly insectivorous flycatchers and warblers (Liu et al., 2020).

284

285

\section{Effect of birds on seed germination rate}

286

287

288

289

290

291

292

293

294

295

296

297

298

299

300

301

302

303

304

305

306

307

308

309

310

311

312

313

314

315

316

317

Bird ingestion may increase the seed germination rates of different plant species, and many fruit plant species, including invasive species, have been shown to benefit from ingestion by frugivorous birds (Combs et al., 2011; Carrion-Tacuri et al., 2012; Czarnecka, Orlowski, \& Karg, 2012; Thabethe et al., 2015).

Our results showed that the seed germination rates from intact fruits of both plant species were lower than from ingested and manually de-pulped seeds (Fig. 4), which was consistent with the results of Barnea, Yom-Tov, \& Friedman (1990), Yagihashi, Hayashida, \& Miyamoto (1999), and Traveset (1998). This suggested that local frugivorous bird ingestion similarly and positively affected the germination success of alien and native plant species in the study site. The local birds were legitimate seed dispersers/seed predators or pulp peckers of the fleshy-fruited alien plant. The higher seed germination rate of ingested and manually de-pulped seeds may be attributed to the removal of pulp or appropriate seed coat abrasion, but more trials are necessary to prove this conclusion. The final cumulative germination percentage of the native plant species was similar to that of the alien plant species across three different groups. This suggested that the seed dispersal pattern in $P$. americana was similar to that of $C$. japonica.

Many alien plants have interfered with the dynamic between frugivores and native plants (Farwig \& Berens, 2012). Alien species with abundant and nutritious fruits may prevent birds from visiting native plants. This reduces seed dispersal success and recruitment (Hansen \& Müller, 2009; Mokotjomela et al., 2013). In our study, the alien plant $P$. americana had more abundant fruits and attracted more visiting frugivores than the native plant $C$. japonica. The mutualistic interaction between the alien plant and native frugivores is likely to lead to an invasion with a negative impact on the local ecological environment. Appropriate measures should be taken to control a potential invasion of $P$. americana in the study site.

\section{Conclusion}

The alien species $P$. americana showed similar fruit characteristics to the native plant species $C$. japonica. A mutualistic seed dispersal relationship between the alien plant species and local frugivorous birds, similar to the native one, has been established. Local frugivorous bird digestion could promote the seed germination rate of the alien plant, and its seedling was more likely to occupy the forest gap microhabitat than the native plant seedling. All of these factors have allowed the alien plant species $P$. americana to remain and rapidly expand in Dongchuan coastal seawall forest. 
318

319

320

321

322

323

324

325

326

327

328

329

330

331

332

333

334

335

336

337

338

339

340

341

342

343

344

345

346

347

348

349

350

351

352

353

354

355

\section{Acknowledgements}

We are grateful to Shengbin Xie, Yong Zhang, and Baodong Yuan for their help in data processing. We also thank the staff at the Dafeng Milu National Nature Reserve for their contributions to this field of study.

\section{References}

Aslan CE. 2011. Implications of newly-formed seed-dispersal mutualisms between birds and introduced plants in northern California, USA. Biological Invasions, 13:2829-2845.

Barnea A, Yom-Tov Y, Friedman J. 1990. Differential germination of two closely related species of Solanum in response to bird ingestion. Oikos, 57: 222-228.

Bitani N, Ehlers Smith DA, Ehlers Smith YC, Downs CT. 2020. Functional traits vary among fleshy-fruited invasive plant species and their potential avian dispersers. Acta Oecologica, DOI:10.1016/j.actao.2020.103651.

Buckley YM, Anderson S, Catterall CP, Corlett RT, Engel T, Gosper CR, Nathan R, Richardson DM, Setter M, Spiegel O, Vivian-Smith G, Voigt FA, Weir GES, Westcott DA. 2006. Management of plant invasions mediated by frugivore interactions. Journal of Applied Ecology, 43: 848-857.

Burnham KM, Lee TD. 2010. Canopy gaps facilitate establishment, growth, and reproduction of invasive Frangula alnus in a Tsuga canadensis dominated forest. Biological Invasions, 12(6): 1509-1520.

Butler DW, Green RJ, Lamb D, McDonal WJF, Forster PI. 2007. Biogeography of seeddispersal syndromes, life forms and seed sizes among woody rain forest plants in Australias subtropics. Journal of Biogeography, 34(10): 1736-1750.

Camargo P, Rodrigues S, Piratelli AJ, Oliveira PS, Christianini AV. Interhabitat variation in diplochory: Seed dispersal effectiveness by birds. Perspectives in Plant Ecology, Evolution and Systematics, 2019, 38: 48-57.

Carrion-Tacuri J, Berjano R, Guerrero G, Figueroa E, Tye A, Castillo JM. 2012. Predation on seeds of invasion Lantana camara by Darwin' finches in Galapagos Islands. Wilson Journal Ornithology, 124: 338-344.

Combs JK, Reichard SH, Groom MJ, Wilderman DL, Camp PA. 2011. Invaisve competitor and native seed predators contribute to rarity of the narrow endemic Astragalus sinuatus Piper. Ecological Applications, 21: 2498-2509.

Czarnecka J, Orlowski G, Karg J. 2012. Endozoochorous dispersal of alien and native plants by two palearctic avian frugivores with special emphasis on invasive giant goldenrod Sokidago gigantea. Central European Journal of Biology, 7: 895-901.

Drummond BA. 2005. The selection of native and invasive plants by frugivorous birds in Maine. Northeast Naturalist, 12: 33-44. 
356

357

358

359

360

361

362

363

364

365

366

367

368

369

370

371

372

373

374

375

376

377

378

379

380

381

382

383

384

385

386

387

388

389

390

391

392

393

394

395

Duan Q, Goodale E, Quan RC. 2013. The effect of color on fruit selection in six Tropical Asian birds. The Condor, 115(3): 623-629.

Dugger PJ, Blendinger PG, Böhning-Gaese K, Chama L, Correia M, Dehling DM, Emer C, Farwig N, Fricke EC, Galetti M, García D, Grass I, Heleno R, Jacomassa FAF, Moraes S, Moran C, Muñoz MC, Neuschulz EL, Nowak L, Piratelli A, Pizo MA, Quitián M, Rogers HS, Ruggera RA, Saavedra F, Sánchez MS, Sánchez R, Santillán V, Schabo DG, Ribeiro da Silva F, Timóteo S, Traveset A, Vollstädt MGR, Schleuning M. 2018. Seed-dispersal networks are more specialized in the Neotropics than in the Afrotropics. Global Ecology and Biogeography, 28(2): 248-261.

Farwig N, Berens DG. 2012. Imagine a world without seed dispersers: a review of threats, consequences and future directions. Basic and Applied Ecology, 13:109-115.

Galindo-González J, Guevara S, Sosa VJ. Bat-and bird-generated seed rains at isolated trees in pastures in a tropical rainforest. Conservation Biology, 2000, 14(6): 1693-1703.

Gosper CR, Stansbury CD, Vivian-Smith G. 2005. Seed dispersal of fleshy-fruited invasive plants by birds: contributing factors and management options. Diversity and Distributions, 11:549-558.

Hansen CJ, Goertzen LR. 2006. Cayratia japonica (Vitaceae) Naturalized in Alabama. Castanea, 71(3): 248-251.

Hansen DM, Müller CB. 2009. Invasive ants disrupt gecko pollination and seed dispersal of the endangered plant Roussea simplex in Mauritius. Biotropica, 41:202-208.

Kawakami K, Mizusawa L, Higuchi H. 2009. Re-established mutualism in a seed-dispersal system consisting of native and introduced birds and plants on the Bonin Islands, Japan. Ecological Research, 24: 741-748.

Kollmann J, Frederiksen L, Vestergaard P, Bruun HH. 2007. Limiting factors for seedling emergence and establishment of the invasive non-native Rosa rugosa in a coastal dune system. Biol Invasions, 9: 31-42.

Korine C, Kalko EKV, Herre EA. 2000. Fruit characteristics and factors affecting fruit removal in a Panamanian community of strangler figs. Oecologia, 123:560-568.

Leishman MR, Wright IJ, Moles AT, Westoby M. 2000. The evolutionary ecology of seed size. In: Fenner M (ed) Seeds: the ecology of regeneration in plant communities, 2nd edn. CABI Publishing, Wallingford, pp 31-57.

Levey DJ, Martínez del Rio C. 2001. It takes guts (and more) to eat fruit: lessons from avian nutritional ecology. Auk, 118:819-831.

Li N, Wang Z, Zhang S, Yan C, Li XH, Lu CH. 2019. Importance of bird traits for seed dispersal patterns of co-fruiting trees in a patchy forest. Integrative Zoology, 14: 470-478.

Li N, Yang W, Fang S, Li X, Liu Z, Leng X, An S. 2017. Dispersal of invasive Phytolacca americana seeds by birds in an urban garden in China. Integrative Zoology, 12(1): 26-31.

Liu B, Xu P, Xue DD, An YT, Lu CH. 2020. Nest site selection and niche differentiation of Eophonamigratoria and Dicrurusmacrocercus in Yancheng Coastal Seawall Forest. Chinese Journal of Ecology, 39(1): 186-193. 
396

397

398

399

400

401

402

403

404

405

406

407

408

409

410

411

412

413

414

415

416

417

418

419

420

421

422

423

424

425

426

427

428

429

430

431

432

433

Lovas-Kiss A, Vincze O, Kleyheeg E, Sramkó G, Laczkó L, Fekete R, Molnár A, Green AJ. 2020. Seed mass, hardness, and phylogeny explain the potential for endozoochory by granivorous waterbirds. Ecology and Evolution, 10:1413-1424.

Lu C. 2003. Biology of mistletoe (Viscum coloratum) and its seed dispersal frugivorous birds. Acta Ecologica Sinica, 23(4): 834-839.

Martins SV, Júnior RC, Rodrigues RR, Gandolf S. 2004. Colonization of gaps produced by death of bamboo clumps in a semideciduous mesophytic forest in south-eastern Brazil. Plant Ecology, 172(1): 121-131.

McDonnell MJ, Stilers EW, Cheplick G, Armesto JJ. 1984. Bird-dispersal of Phytolacca americana $\mathrm{L}$. and the influence of fruit removal on subsequent fruit development. American Journal of Botany, 71(7): 895-901.

Mokotjomela TM, Musil CF, Esler KJ. 2013. Frugivorous birds visit fruits of emerging alien shrub species more frequently than those of native shrub species in the South African Mediterranean climate region. South African Journal of Botany, 86:73-78.

Moles AT, Acherly DD, Webb CO, Tweddle JC, Dickie JB, Westoby M. 2005. A brief history of seed size. Science, 307: 576-580.

Morán-López T, González-Castro A, Morales JM, Nogales M. Behavioural complementarity among frugivorous birds and lizards can promote plant diversity in island ecosystems. Functional Ecology, 2020, 34:182-193.

Prado FA. 2013. Feeding behavior, bird visitation, and seed dispersal in guarea macrophylla and trichiliaquadrijuga.Ornitologia Neotropical, 24: 459-468.

R Core Team. 2018. R: A language and environment for statistical computing. R Foundation for Statistical Computing, Vienna, Austria. http://www.R-project.org/. Accessed 15 March 2018.

Renne IJ, Barrow WC Jr, Johnson Randall LA, Bridges Jr WC. 2002. Generalized avian dispersal syndrome contributes to Chinese tallow tree (Sapiumsebiferum, Euphorbiaceae) invasiveness. Diversity and Distributions, 8:285-295.

Rey PJ, Gutiérrez JE, Alcántara J, Valera F. 1997. Fruit size in wild olives: implications for avian seed dispersal. Functional Ecology, 11:611-618.

Ridenour WM, Callaway RM. 2001. The relative importance of allelopathy in interference: the effects of an invasive weed on a native bunchgrass. Oecologia,126 :444-450.

Saavedra F, Hensen I, Beck SG, Böhning-Gaese K, Lippok D, Töpfer T, Schleuning M. 2014. Functional importance of avian seed dispersers changes in response to human induced forest edges in a tropical seed-dispersal networks. Oecologia, 176: 837-848.

Sallabanks R. 1993. Hierarchical mechanisms of fruit selection by an avian frugivore. Ecology, 74: 1326-1336.

Schierenbeck KA. 2004. Japanese Honeysuckle (Lonicera japonica) as an invasive species; History, ecology, and context. Critical Reviews in Plant Sciences, 23(5): 391-400. 
434 Schleuning M, Blüthgen N, Flörchinger M, Braun J, Schaefer HM, Böhning-Gaese K.. 2011.

435 Specialization and interaction strength in a tropical plant-frugivore network differ among 436 forest strata. Ecology, 92(1): 26-36.

437 Schneiberg I, Boscolo D, Devoto M, Marcilio-Silva V, Dalmaso CA, Ribeiro JW, Ribeiro MC, 438 Guaraldo AC, Niebuhr BB, Varassin IG. 2020. Urbanization homogenizes the interactions 439 of plant-frugivore bird networks. Urban Ecosystems, 23: 457-470.

440 Traveset A. 1998. Effect of seed passage through vertebrate frugivores' guts on germination: a 441 review. Perspectives in Plant Ecology, Evolution and Systematics, 1:151-190.

442 Thabethe V, Wilson A, Hart LA, Downs CT. 2015. Ingestion by an invasive parakeet species

443 reduces germination success of invasive alien plants relative to ingestion by indigenous

444 turaco species in South Africa. Biological Invasions, 17: 3029-3039.

445 Wang B, Ives AR. 2017. Tree-to-tree variation in seed size and its consequences for seed

446 dispersal versus predation by rodents. Oecologia, 183: 751-762.

447 Wenny DG. 2001. Advantages of seed dispersal: a re-evaluation of directed dispersal.

448 Evolutionary Ecology Research, 3:51-74.

449 Whelan CJ, Willson MF. 1994. Fruit choice in migrating North American birds: field and aviary 450 experiments. Oikos, 71:137-151.

451 Willamson M, Fitter A. 1996. The varying success of invaders. Ecology, 77: 1661-1666.

452 Wilson AL, Downs CT. 2012. Knysna Turacos (Tauracocorythaix) do not improve seed

453 germination of ingested fruit of some indigenous South African tree species. South African 454 Journal Botany, 78:55-62.

455 Wu JX, Delparte DM, Hart PJ. 2014. Movement patterns of a native and non-native frugivore in 456 Hawaii and implications for seed dispersal. Biotropica, 46(2): 175-182.

457 Yagihashi T, Hayashida M, Miyamoto T. 1999. Effects of bird ingestion on germination of two 458 Prunus species with different fruit-ripening seasons. Ecological Research, 14(1):71-76. 


\section{Table 1 (on next page)}

Fruit characteristics and plant density of the two plant species in the study site. Number in brackets indicates the sample size. Mean and SD are displayed in the table. 


\begin{tabular}{lll}
\hline & Cayratia japonica & Phytolacca americana \\
\hline Fruit type & Berry & Berry \\
Fruit size (mm) & $10.0 \pm 0.9(20)$ & $7.9 \pm 0.7(20)$ \\
Fruit shape and color & Round, black & Round, Purple black \\
Fruit ripening period & August to October & August to October \\
Fruit height (m) & $0.2 \pm 0.1(20)$ & $1.3 \pm 0.3(20)$ \\
Plant density (individuals $\left./ \mathrm{m}^{2}\right)$ & $0.5 \pm 0.3(20)$ & $0.1 \pm 0.1(20)$ \\
\hline
\end{tabular}

1 


\section{Table 2 (on next page)}

Bird feeding behaviors on the native and alien plant species. Number in brackets indicates the sample size. Mean and SD are displayed in the table, except for feeding frequency which represents the total number of visits. 


\begin{tabular}{|c|c|c|c|c|c|c|c|c|c|c|}
\hline \multirow[t]{2}{*}{ Bird species } & \multicolumn{2}{|c|}{$\begin{array}{c}\text { Feeding frequency } \\
\text { /times }\end{array}$} & \multicolumn{2}{|c|}{ Feeding time/s } & \multicolumn{2}{|c|}{$\begin{array}{c}\text { Number of consumed fruits } \\
\text { per visit }\end{array}$} & \multicolumn{2}{|c|}{ First stopping distance/m } & \multirow{2}{*}{$\begin{array}{l}\text { Feeding } \\
\text { pattern }\end{array}$} & \multirow{2}{*}{$\begin{array}{c}\text { Seasonal } \\
\text { type }\end{array}$} \\
\hline & $\mathbf{C Y}$ & PA & CY & PA & CY & $\mathbf{P A}$ & CY & PA & & \\
\hline Pycnonotus sinensis & 4.0 & 65.0 & $10.0 \pm 7.1(4)$ & $14.2 \pm 7.7(65)$ & $1.5 \pm 0.6(4)$ & $4.1 \pm 1.9(65)$ & $9.3 \pm 7.2(4)$ & $13.4 \pm 7.7(65)$ & $\mathrm{S}$ & $\mathrm{R}$ \\
\hline Turdus merula & 3.0 & 18.0 & $6.7 \pm 3.5(3)$ & $7.3 \pm 3.2(18)$ & $1.3 \pm 0.6(3)$ & $3.7 \pm 2.4(18)$ & $25.0 \pm 5.0$ & $28.6 \pm 14.6(18)$ & $\mathrm{S}$ & $\mathrm{R}$ \\
\hline Cyanoptila cyanomelana & 0 & 11.0 & 0 & $5.2 \pm 3.5(11)$ & 0 & $1.8 \pm 1.2(11)$ & 0 & $8.3 \pm 5.3(11)$ & $\mathrm{S}$ & $\mathrm{T}$ \\
\hline Sturnus cineraceus & 11.0 & 9.0 & $26.9 \pm 17.6(11)$ & $10.1 \pm 5.3(9)$ & $1.9 \pm 0.8(11)$ & $4.6 \pm 2.1(9)$ & $75.0 \pm 47.0(11)$ & $70.0 \pm 26.0(9)$ & $\mathrm{S}$ & $\mathrm{R}$ \\
\hline Pica pica & 35.0 & 9.0 & $16.7 \pm 10.6(35)$ & $10.0 \pm 6.5(9)$ & $2.1 \pm 1.2(35)$ & $4.2 \pm 2.8(9)$ & $29.9 \pm 16.1(35)$ & $23.3 \pm 7.1(9)$ & $\mathrm{S}$ & $\mathrm{R}$ \\
\hline Oriolus chinensis & 12.0 & 0 & $11.9 \pm 8.1(12)$ & 0 & $2.6 \pm 1.1(12)$ & 0 & $31.9 \pm 25.1(12)$ & 0 & $\mathrm{~S}$ & $\mathrm{~T}$ \\
\hline Turdus hortulorum & 6.0 & 4.0 & $14.5 \pm 6.3(6)$ & $7.8 \pm 5.7(4)$ & $1.8 \pm 0.8(6)$ & $2.8 \pm 2.2(4)$ & $42.5 \pm 16.7(6)$ & $19.3 \pm 10.3(4)$ & $\mathrm{S}$ & $\mathrm{T}$ \\
\hline Paradoxornis webbianus & 0 & 17.0 & 0 & $5.8 \pm 2.9(17)$ & 0 & $3.6 \pm 1.8(17)$ & 0 & $6.7 \pm 2.3(17)$ & $\mathrm{S} / \mathrm{P}$ & $\mathrm{R}$ \\
\hline Parus major & 1.0 & 13.0 & $5.0(1)$ & $6.8 \pm 3.4(13)$ & $1.0(1)$ & $2.2 \pm 0.9(13)$ & $12.0(1)$ & $12.2 \pm 4.3(13)$ & $\mathrm{S} / \mathrm{P}$ & $\mathrm{R}$ \\
\hline Eophona migratoria & 13.0 & 4.0 & $20.8 \pm 13.7(13)$ & $10.0 \pm 4.8(4)$ & $1.7 \pm 0.9(13)$ & $4.5 \pm 3.1(4)$ & $26.0 \pm 12.4(13)$ & $15.0 \pm 5.8(4)$ & $\mathrm{S} / \mathrm{P}$ & $\mathrm{R}$ \\
\hline Emberiza spodocephala & 0 & 13.0 & 0 & $11.6 \pm 3.6(13)$ & 0 & $2.0 \pm 0.9(13)$ & 0 & $7.2 \pm 4.6(13)$ & $\mathrm{S} / \mathrm{P}$ & $\mathrm{W}$ \\
\hline
\end{tabular}

1 CY: Cayratia japonica; PA: Phytolacca americana

2 Feeding pattern: S: Swallow; P: Pecking

3 Seasonal type: R: Resident birds; T: Travel birds; W: Winter birds 
Figure 1

Relationship between percent fully ripen fruits and percent of fruit missing caused by bird visiting. Percent missing fruits are based on the remaining fruits of each sampled plants $(n=10)$. Simple linear regression is used for statistical analysis.

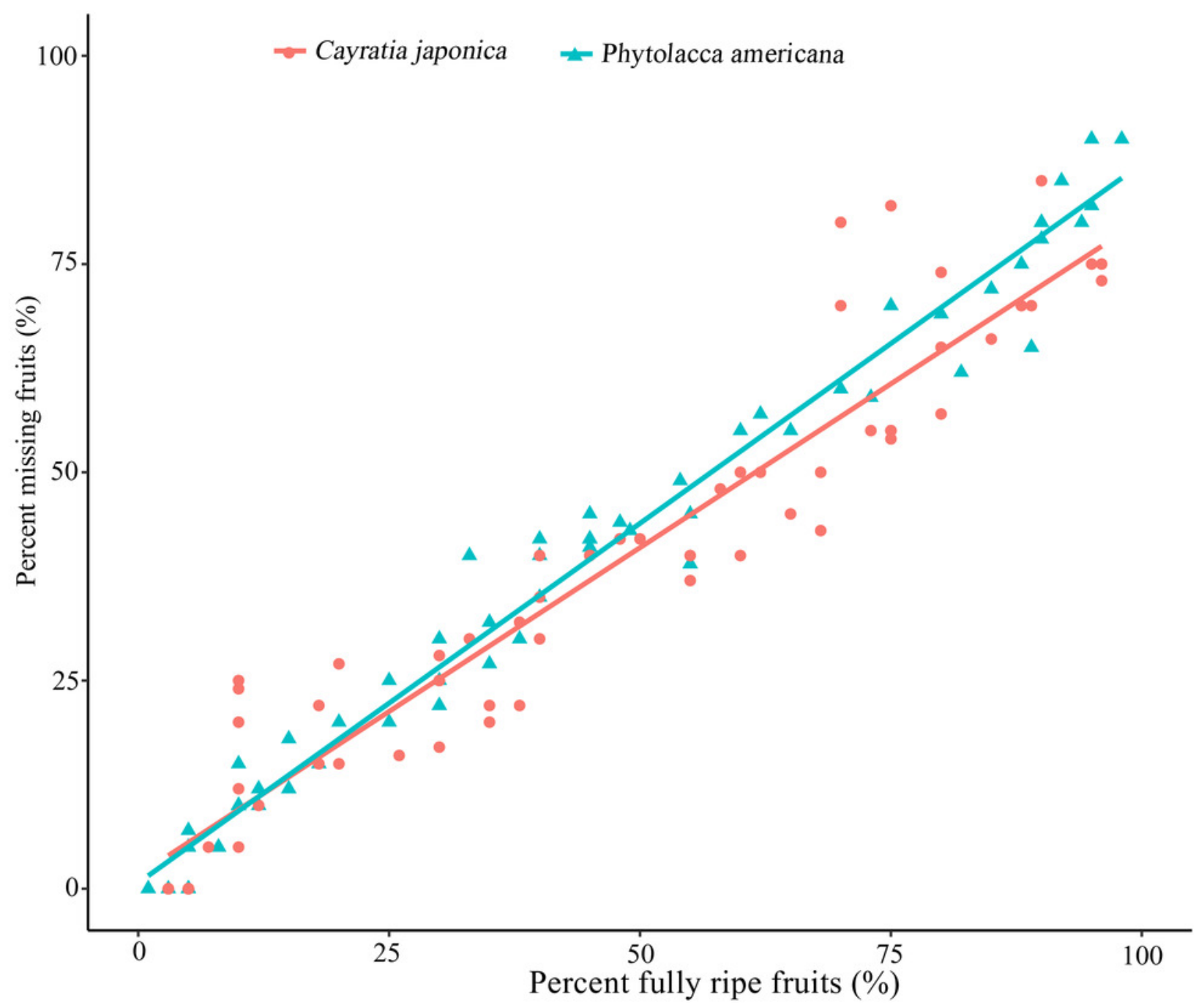




\section{Figure 2}

Correspondence relationship between avian frugivores and fruiting plants based on feeding behaviors. Widths of connecting lines denote the number of observed interactions (wider represents higher intensity of visiting).

Avian frugivores: PS: Pycnonotus sinensis; PP: Pica pica; TM: Turdus merula; SC: Sturnus cineraceus; EM: Eophona migratoria; PW: Paradoxornis webbianus; PM: Parus major; ES: Emberiza spodocephala; OC: Oriolus chinensis; CC: Cyanoptila cyanomelana; TH: Turdus hortulorum

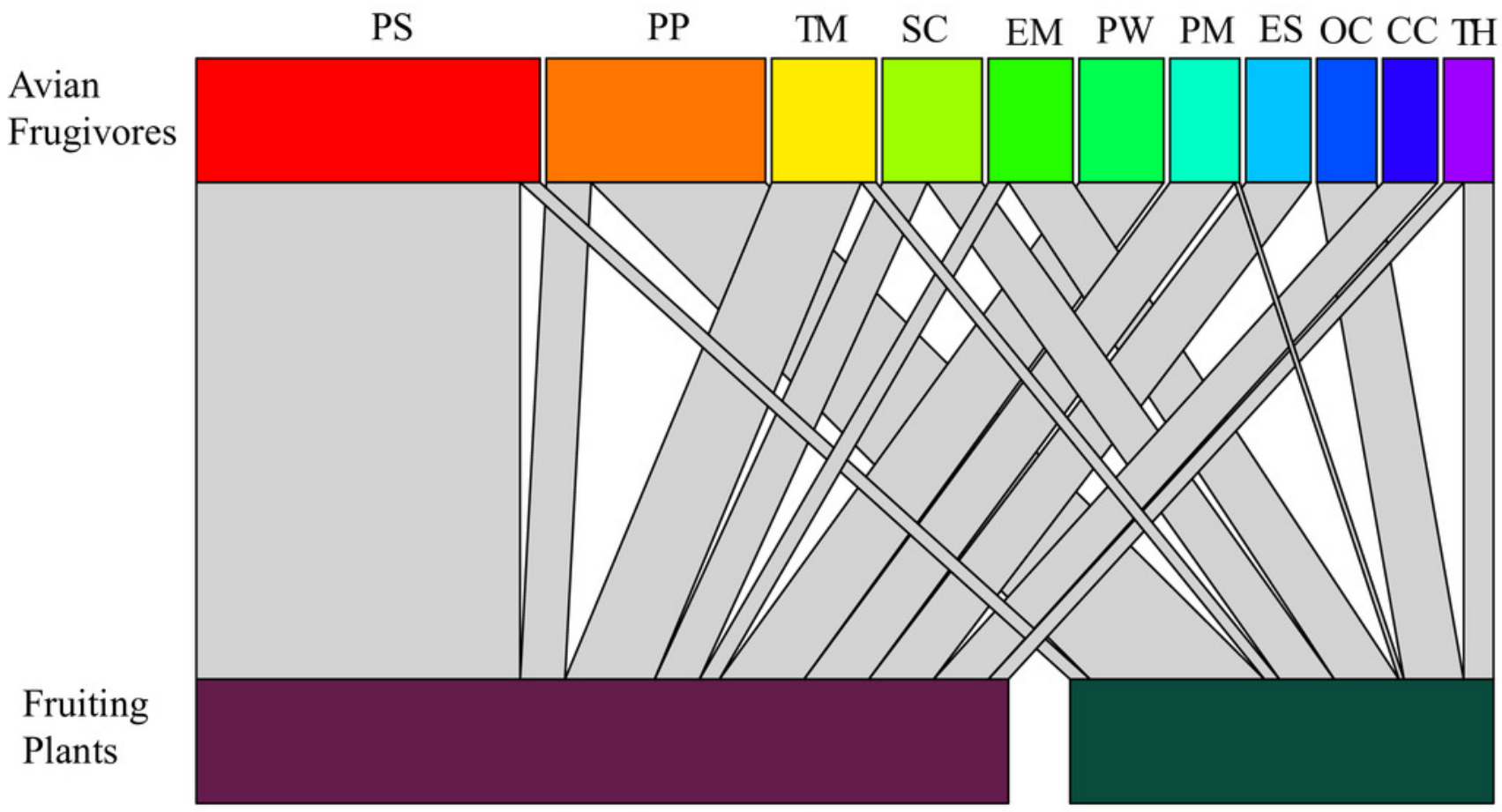

Phytolacca americana

Cayratia japonica 
Figure 3

Cumulative seed germination rates of the two plant species in 3 different groups. Each group contains 100 seeds.
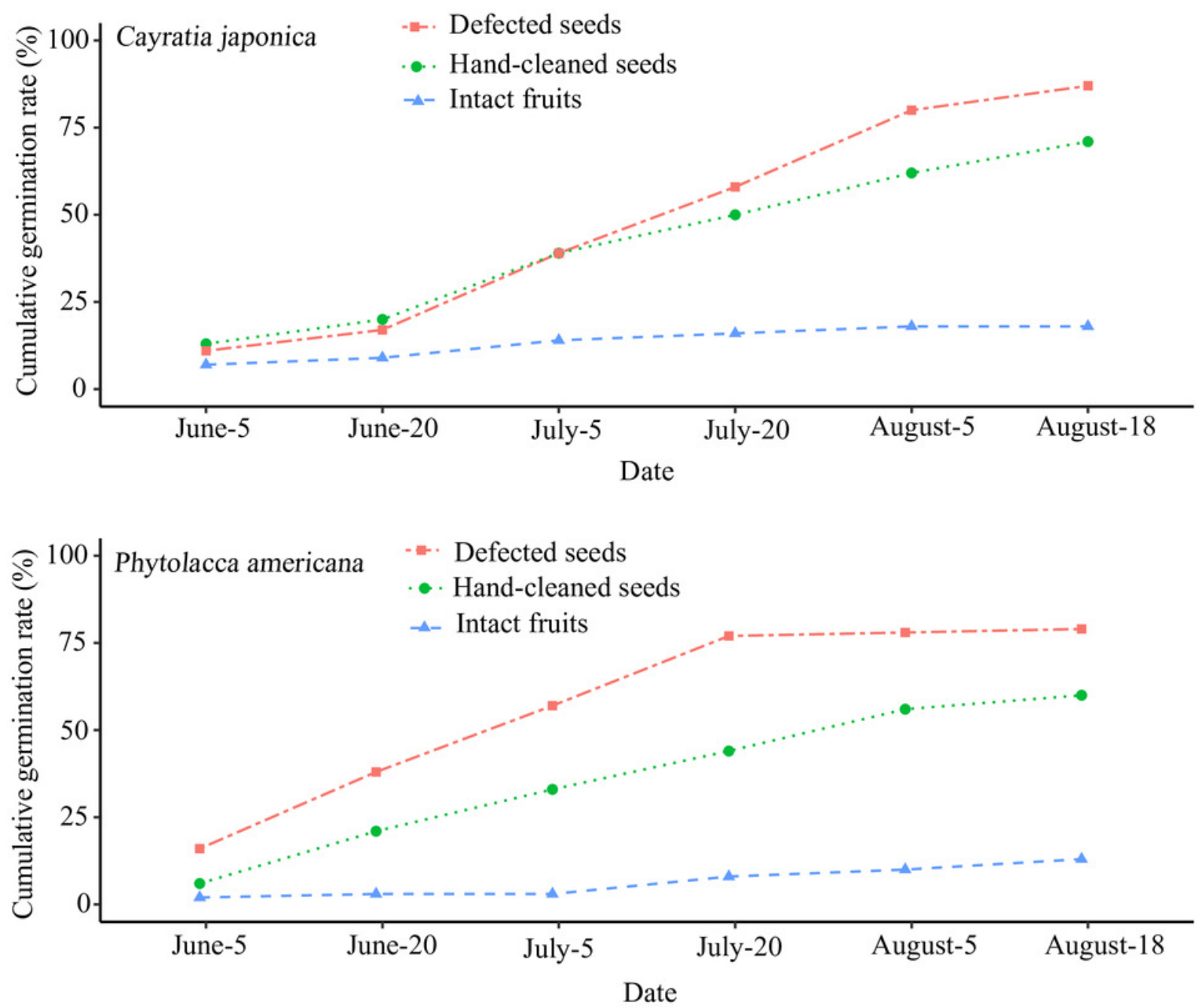
Figure 4

The mean seedling number of the native and alien plant species growing in 2 different microhabitats. Thirty plots $(r=25 \mathrm{~m})$ are investigated. Error bars show the standard deviation.

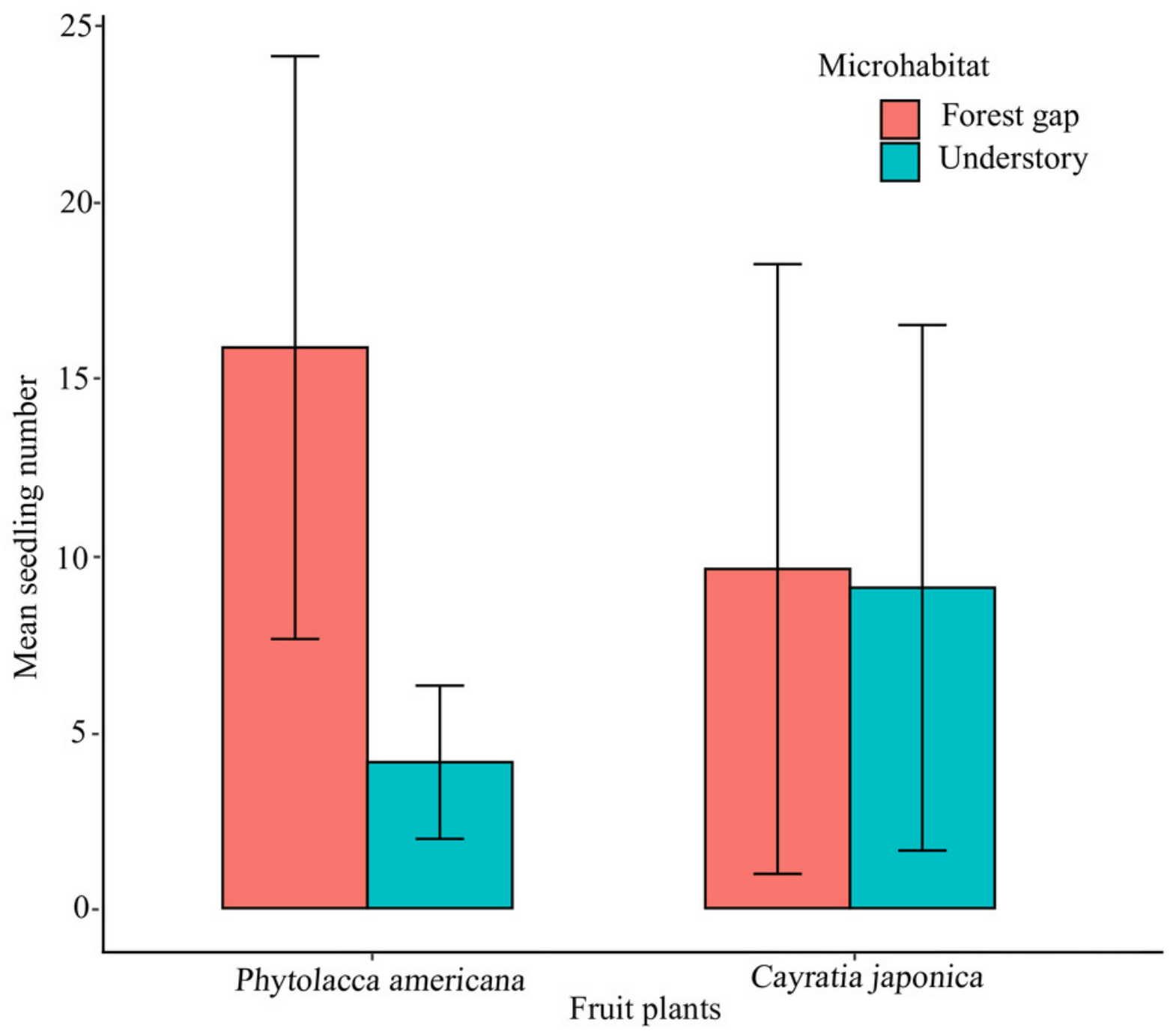

